\title{
Implementation of a Non-Linear Regression Model in Rolling Bearing Diagnostics
}

\author{
Biljana SAVIĆ, Vlade UROŠEVIĆ, Nebojša IVKOVIĆ, Ivan MILIĆEVIĆ*, Marko POPOVIĆ, Nenad GUBELJAK, Goran ŠINIKOVIĆ
}

\begin{abstract}
The reliable operation of a mechanical system is dependent on the condition of installed rolling bearings. This paper presents a measuring system and equipment for analyzing the condition of rolling bearings. The developed system is a modular device (VibroLog) for measuring several diagnostic parameters for bearings, including vibration, number of revolutions, temperature and sound pressure. The device is a data collector and analyzer. Software in the Java programming language for the analysis and presentation of data obtained by VibroLog has also been developed. This paper is concerned with the development of a mathematical model for the evaluation and prediction of the qualitative state of rolling bearings in real operating conditions. It also presents results of measurement and mathematical modelling of the results. The model was formed by non-linear regression analysis as one of the most widely used statistical techniques. The analysis of the experimental data showed that the rate of change of a variable is proportional to its actual value. The model was tested on several rolling bearings having different degrees of damage. The developed model makes it possible to evaluate and predict the condition of the bearing by measuring the sound pressure level, which is simpler than vibration measurement in real operating conditions. During testing, the model generated results within the prediction error limits. The developed vibrodiagnostic system and the created model enable condition assessment and prediction for a wide range of rolling bearings
\end{abstract}

Keywords: diagnostics; non-linear regression analysis; prediction; rolling bearings

\section{INTRODUCTION}

Rolling bearings are widely used in various mechanical systems. The reliable operation of a mechanical system is dependent on the condition of installed rolling bearings. Different defects occur in bearings during their operation, depending on operating and environmental conditions. Early detection of local defects through vibration signal analysis is essentially a vital issue [1-10].

Hidden faults and defects in rolling bearings can cause serious damage to machines, vehicles and large systems. Therefore, rolling bearings have been the subject of many studies.

A well-grounded diagnostic methodology can provide a simple way to identify the degree of damage to the bearing i.e. determine its remaining useful life. These data are of vital importance for the concept of preventive proactive maintenance of all systems containing bearings [11].

Vibrodiagnostics is a simple and easy method for determining the cause of bearing damage. This is one of the reasons why particular attention in developed countries has been paid to the preventive maintenance of bearings, condition monitoring, and replacements during planned stoppages. Also, specific importance has been given to their maintenance, mounting and dismounting to ensure they have a long service life [12-15].

Vibration measurement instruments and testing systems are mostly created by manufacturers of machine elements and companies specializing in vibrodiagnostics. They often set up vibration test specifications and testing procedures, based on long-standing experience and vast knowledge in the field of vibrodiagnostics. Vibration tests can offer a structured approach to understanding the mechanical system operation and the cause of failures and damage.

This paper presents a measuring system and equipment for analyzing the condition of rolling bearings. The developed system is a modular device for measuring several diagnostic parameters of rolling bearings, including vibrations, number of revolutions, temperature and sound pressure. The device is a data collector and analyzer.

The measuring system has been designed and created at the Department of Theory of Mechanisms and Machines, Faculty of Mechanical Engineering, University of Belgrade, where rolling bearing testing was conducted [16].

Under real operating conditions, it is not always possible to measure all vibrodiagnostic parameters. Machine operating conditions, planned stoppages, replacements and other factors are potential constraints to parameter measurements in complex systems.

Finding a relationship between these parameters and creating an appropriate model would improve methods of vibrodiagnostics i.e. condition monitoring, if the value of a single parameter could be used for drawing conclusions about the condition of the bearing [17-26].

This paper presents the development of one such mathematical model using regression analysis.

The model was created by identifying patterns in the distribution of the experimental data and their interrelationships, based on non-linear regression analysis $[27,28]$. The analysis of the experimental data showed that the rate of change of a variable is proportional to its actual value. We chose to use an exponential function, knowing that the exponential function arises naturally as a mathematical model in such situations. The adequacy of the model was assessed by Fischer's test.

The model was tested on several rolling bearings having different degrees of damage. By sound intensity measurement, the model generated results within the prediction error limits.

The developed vibrodiagnostic system and the created model make it possible to evaluate and predict the condition of a wide range of rolling bearings for a number of different types of machines (ISO 20816-1:2016).

Since rolling bearings are the most widely used machine elements, which are also considered to be vital components in assemblies, monitoring of their condition increases the reliability of the entire mechanical system and improves its operational characteristics and performance. 


\section{STRUCTURE OF THE BEARING TESTING SYSTEM}

During the testing of the condition of rolling bearings using the newly developed diagnostic system - VibroLog (Fig. 1 (4)), a comparative analysis is conducted to evaluate three important parameters that indicate the degree of damage to the bearing, vibrations $\left(V_{\mathrm{rms}}\right)$, sound pressure $(P)$ and temperature $(T)$. These parameters presented in Fig. 1 are measured by a vibration sensor (2), a microphone (1), a temperature sensor (3), and photoelectric sensors (5), respectively.

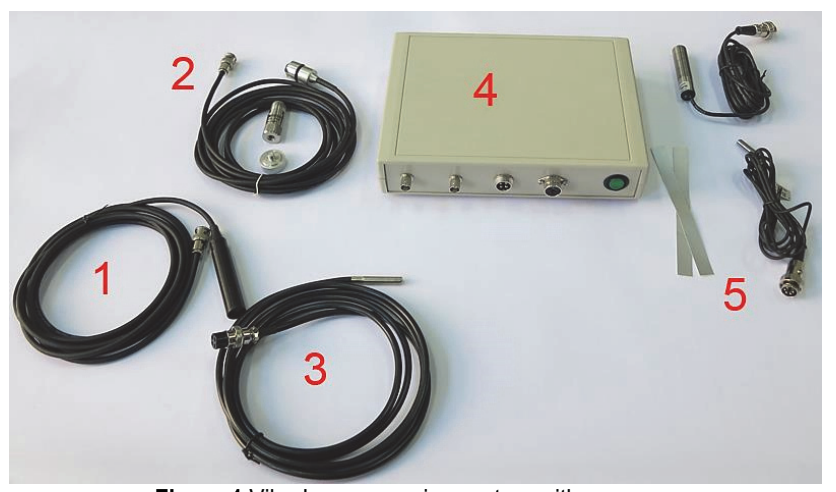

Figure 1 VibroLog measuring system with sensors

A test bench fitted with sensors for bearing testing is presented in Fig. 2.

Fig. 3 shows a VibroLog measuring device connected to a computer on which measured values of $V_{\text {rms }}, P, T$ and number of shaft revolutions, and various diagrams are presented by means of VibroLogApp software [29].

The diagrams are shown in Fig. 4 for $V$ and $P$ in frequency domain, but the application can also be used for drawing Waterfall charts (Fig. 5).

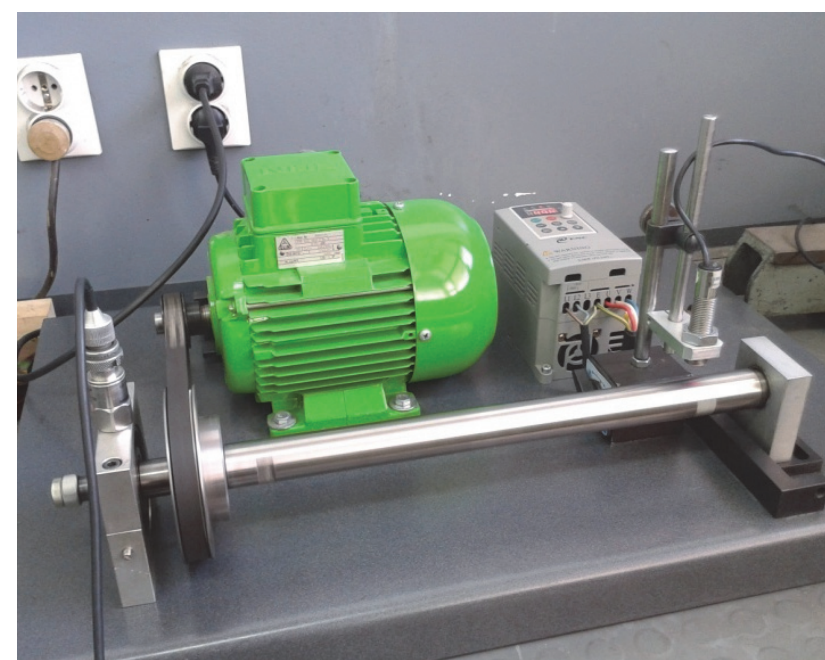

Figure $2 \mathrm{~A}$ test bench fitted with sensors for bearing testing

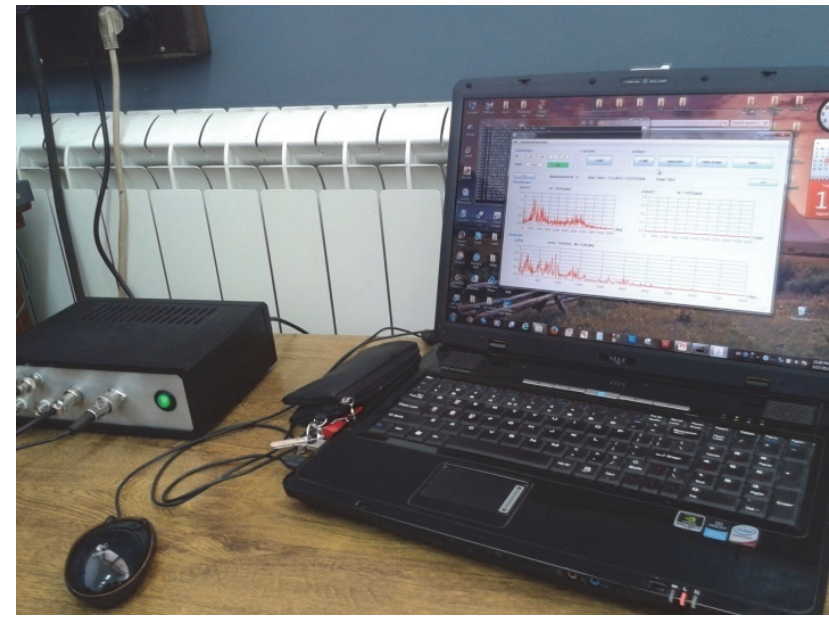

Figure 3 VibroLog measuring system

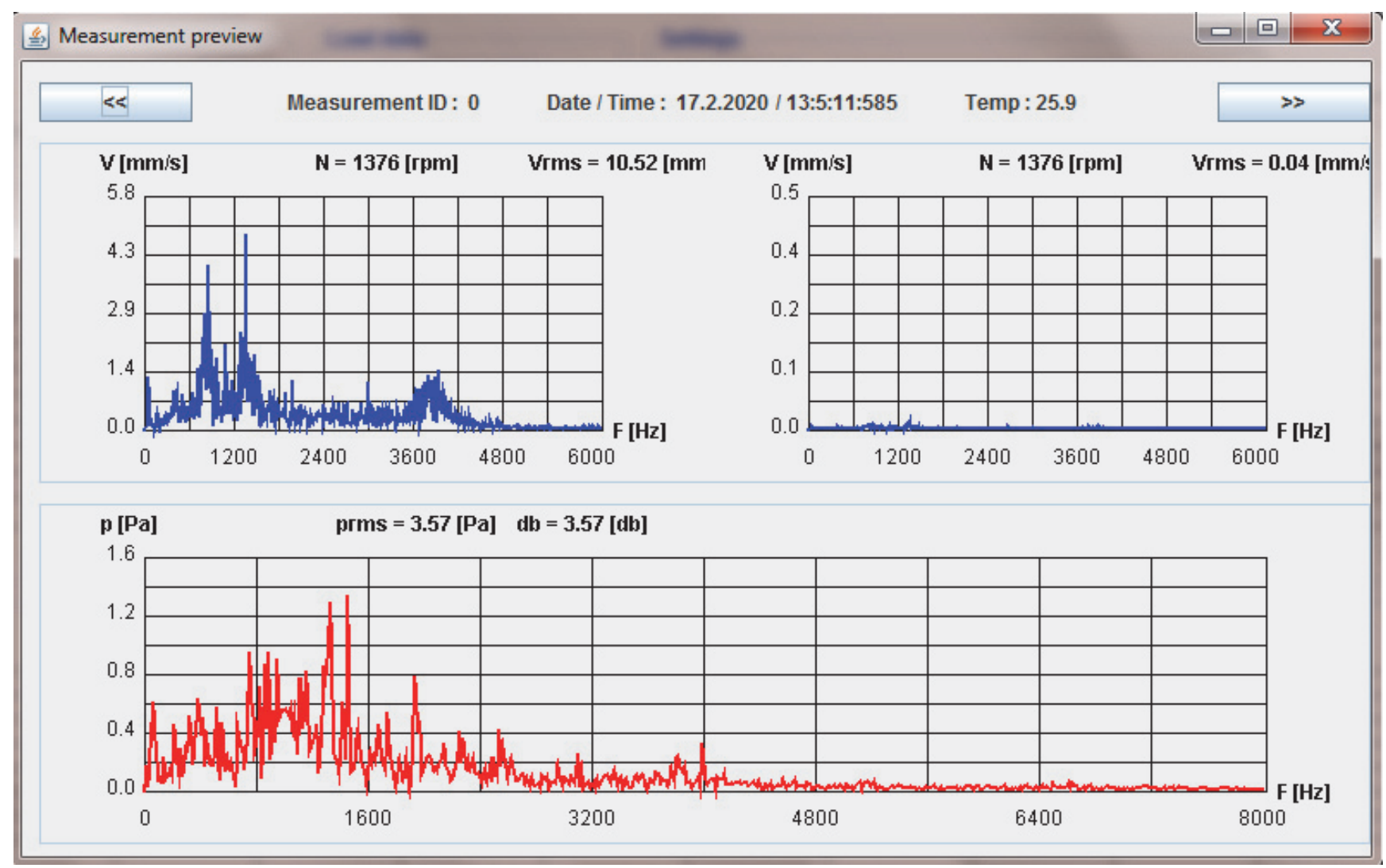

Figure 4 The spectra and the measured values on the bearing No. 13 (FFT diagram) 


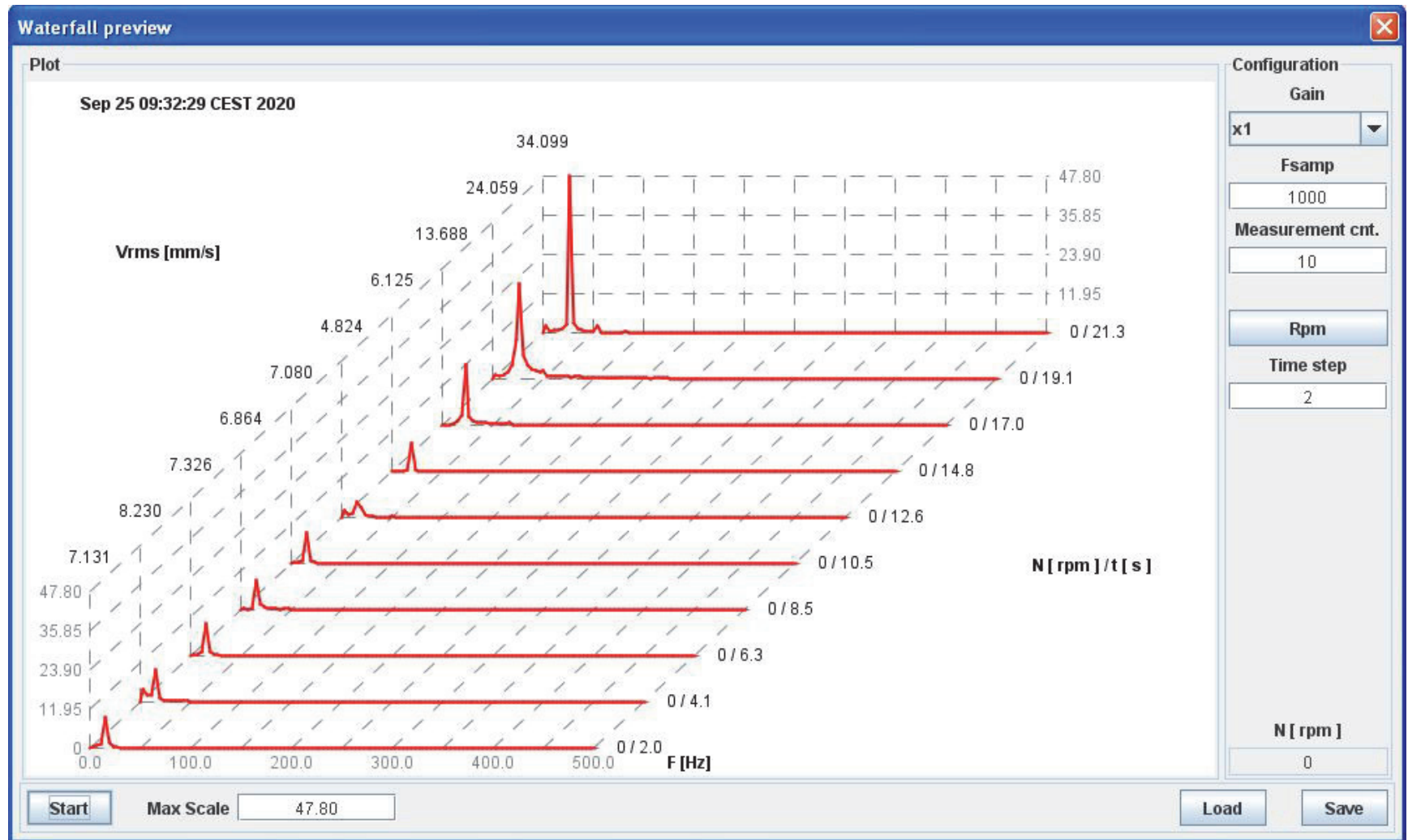

Figure 5 Example of Waterfall charts

\subsection{Measured Parameters \\ 2.1.1 Vibration}

The method most commonly used for testing the condition of bearings is vibration measurement. An increase in bearing vibration at the housing may be due to a defect in the bearing. At the same time, vibrations coming from other sources can cause damage to the bearing. Therefore, the intensity of vibrations at the bearing housing should be measured to check whether they are within the limits specified for the machine.

\subsubsection{Sound Pressure}

Noise measurement, usually in terms of the sound pressure level, is a method used for periodic signals, as in rotating machines. Vibrations emitted by the bearing are transmitted to surrounding structures, causing acoustic noise, which is used for bearing condition analysis. The transformation of sound pressure into an electrical signal is made by an input electroacoustic transducer (microphone), used in this case for sound pressure measurement [29, 30].

\subsubsection{Temperature}

Temperature measurement is a useful and simple method for bearing condition monitoring, since most defects sooner or later lead to an increase in bearing temperature. When two contacting bodies move relative to each other, friction force occurs and the work done is converted into heat. Although very useful, this monitoring method can be used only for bearings with 1 to 5 percent of remaining life i.e. when the harmonics of the fundamental frequency are visible.

\section{MODEL DEVELOPMENT}

\subsection{Experimental Data and Their Analysis}

The experiment is based on a comparative analysis of three important parameters which indicate the degree of bearing damage, including vibration, sound pressure and temperature.

Testing was conducted using the bearing testing equipment, Fig. 2, on type-6306 bearings. Measurements on the bearings were performed in Tab. 1, at three different frequencies: 20, 40 and $60 \mathrm{~Hz}$, and at three different speeds: 461, 924 and 1378 revolutions per minute. Fig. 6 shows a bearing damage levels.

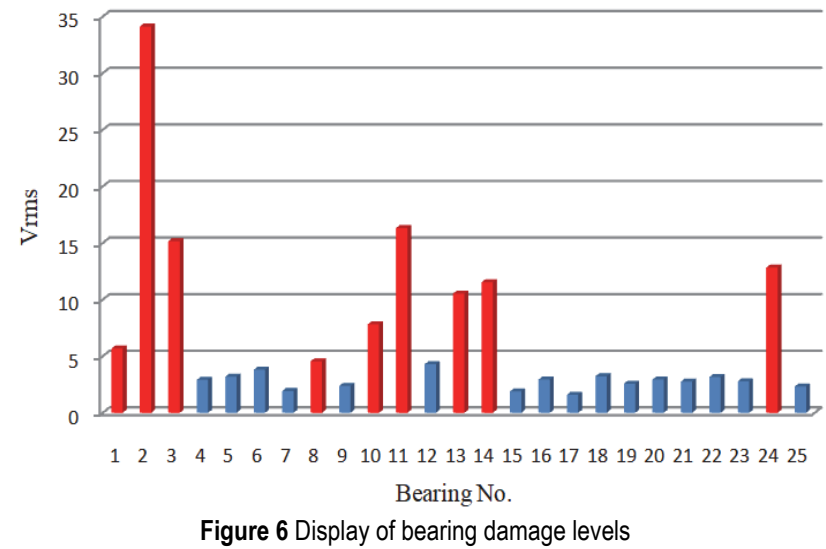

Tab. 2. presents the experimental values for a single set of measurements of parameters used for modeling at 1378 revolutions per minute. 
Table 1 Values measured on the bearings

\begin{tabular}{|c|c|c|c|c|}
\hline $\begin{array}{c}\text { Bearing } \\
\text { No. }\end{array}$ & Revolutions / $\min ^{-1}$ & $V_{\mathrm{rms}} / \mathrm{mm} / \mathrm{s}$ & $P / \mathrm{Pa}$ & $T /{ }^{\circ} \mathrm{C}$ \\
\hline \multirow{3}{*}{1} & 461 & 1.89 & 0.93 & 27.1 \\
\hline & 924 & 4.65 & 2.82 & 26.3 \\
\hline & 1378 & 5.66 & 2.91 & 26.8 \\
\hline \multirow{3}{*}{2} & 461 & 11.99 & 5.45 & 23.6 \\
\hline & 924 & 20.13 & 9.36 & 25.2 \\
\hline & 1378 & 34.11 & 13.65 & 26 \\
\hline \multirow{3}{*}{3} & 461 & 3.38 & 2.46 & 24.4 \\
\hline & 924 & 9.34 & 3.69 & 26.2 \\
\hline & 1378 & 15.15 & 7.01 & 26.5 \\
\hline \multirow{3}{*}{4} & 461 & 1.1 & 0.81 & 23.8 \\
\hline & 924 & 2.25 & 1 & 24.5 \\
\hline & 1378 & 2.9 & 1.6 & 25.1 \\
\hline \multirow{3}{*}{5} & 461 & 1.44 & 0.87 & 26.9 \\
\hline & 924 & 3.24 & 1.42 & 28 \\
\hline & 1378 & 3.19 & 1.82 & 28.3 \\
\hline \multirow{3}{*}{6} & 461 & 1.41 & 0.89 & 25.6 \\
\hline & 924 & 1.72 & 1.4 & 27.2 \\
\hline & 1378 & 3.8 & 1.87 & 28.1 \\
\hline \multirow{3}{*}{7} & 461 & 1.16 & 0.94 & 26.3 \\
\hline & 924 & 1.07 & 0.82 & 28.2 \\
\hline & 1378 & 1.92 & 1.83 & 28.9 \\
\hline \multirow{3}{*}{8} & 461 & 1.43 & 1 & 24.5 \\
\hline & 924 & 2.58 & 1.09 & 26.3 \\
\hline & 1378 & 4.54 & 2.02 & 27 \\
\hline \multirow{3}{*}{9} & 461 & 1.09 & 0.93 & 25.1 \\
\hline & 924 & 1.48 & 1 & 27.6 \\
\hline & 1378 & 2.36 & 1.43 & 28.9 \\
\hline & 461 & 2.56 & 1.21 & 25.4 \\
\hline 10 & 924 & 4.99 & 2.04 & 27.6 \\
\hline & 1378 & 7.8 & 3 & 28.3 \\
\hline & 461 & 3.63 & 1.74 & 24.9 \\
\hline 11 & 924 & 8.98 & 3.79 & 27.4 \\
\hline & 1378 & 16.32 & 16.32 & 30.1 \\
\hline & 461 & 1.52 & 0.96 & 25 \\
\hline 12 & 924 & 2.59 & 1.17 & 26.6 \\
\hline & 1378 & 4.28 & 1.95 & 26.6 \\
\hline & 461 & 2.74 & 1.6 & 25 \\
\hline 13 & 924 & 5.86 & 2.8 & 25.8 \\
\hline & 1378 & 10.52 & 3.57 & 25.9 \\
\hline & 461 & 2.84 & 1.5 & 23.9 \\
\hline 14 & 924 & 7.98 & 2.57 & 24.4 \\
\hline & 1378 & 11.52 & 3.84 & 24.8 \\
\hline & 461 & 1.06 & 0.88 & 25.2 \\
\hline 15 & 924 & 1.18 & 0.83 & 27.3 \\
\hline & 1378 & 1.89 & 1.28 & 27.8 \\
\hline & 461 & 1.48 & 0.57 & 25.1 \\
\hline 16 & 924 & 1.41 & 1.16 & 27.2 \\
\hline & 1378 & 2.93 & 1.62 & 28.6 \\
\hline & 461 & 1.1 & 0.87 & 25.8 \\
\hline 17 & 924 & 0.86 & 0.85 & 27.2 \\
\hline & 1378 & 1.59 & 1.41 & 28.2 \\
\hline & 461 & 1.59 & 0.62 & 26.4 \\
\hline 18 & 924 & 2.03 & 1.07 & 27.5 \\
\hline & 1378 & 3.22 & 2.08 & 28.4 \\
\hline & 461 & 1.32 & 0.83 & 25.8 \\
\hline 19 & 924 & 1.89 & 1.04 & 27.6 \\
\hline & 1378 & 2.56 & 1.47 & 28.8 \\
\hline & 461 & 1.78 & 0.75 & 27.8 \\
\hline 20 & 924 & 1.94 & 1.15 & 29 \\
\hline & 1378 & 2.93 & 1.47 & 29.8 \\
\hline & 461 & 1.51 & 0.9 & 27.9 \\
\hline 21 & 924 & 1.82 & 0.82 & 28.3 \\
\hline & 1378 & 2.75 & 1.74 & 28.7 \\
\hline & 461 & 1.38 & 1.03 & 22.6 \\
\hline 22 & 924 & 1.86 & 1.08 & 23 \\
\hline & 1378 & 3.16 & 1.69 & 22.9 \\
\hline & 461 & 1.49 & 0.9 & 27 \\
\hline 23 & 924 & 1.66 & 0.95 & 28.7 \\
\hline & 1378 & 2.77 & 1.57 & 29.7 \\
\hline & 461 & 3.05 & 1.9 & 26.6 \\
\hline 24 & 924 & 6.4 & 2.75 & 30.1 \\
\hline & 1378 & 12.82 & 7.67 & 30.3 \\
\hline & 461 & 1.17 & 0.72 & 27.1 \\
\hline 25 & 924 & 1.45 & 1 & 29.6 \\
\hline & 1378 & 2.32 & 1.52 & 30.4 \\
\hline
\end{tabular}

Table 2 Values measured on the bearings on 1378 revolutions per minute

\begin{tabular}{|c|c|c|c|}
\hline Bearing No. & $\begin{array}{c}V_{\text {rms }} \\
/ \mathrm{mm} / \mathrm{s}\end{array}$ & $P / \mathrm{Pa}$ & $T /{ }^{\circ} \mathrm{C}$ \\
\hline 15 & 1.89 & 1.28 & 27.8 \\
\hline 9 & 2.36 & 1.43 & 28.9 \\
\hline 19 & 2.745 & 1.47 & 28.8 \\
\hline 23 & 2.77 & 1.57 & 29.7 \\
\hline 4 & 2.9 & 1.6 & 25.1 \\
\hline 16 & 2.93 & 1.62 & 28.6 \\
\hline 22 & 3.16 & 1.69 & 22.9 \\
\hline 5 & 3.19 & 1.82 & 28.3 \\
\hline 6 & 3.8 & 1.87 & 28.1 \\
\hline 12 & 4.28 & 1.95 & 26.6 \\
\hline 8 & 4.54 & 2.02 & 27 \\
\hline 1 & 5.66 & 2.91 & 26.8 \\
\hline 10 & 7.8 & 3 & 28.3 \\
\hline 13 & 10.52 & 3.57 & 25.9 \\
\hline 14 & 11.52 & 3.84 & 24.8 \\
\hline
\end{tabular}

\subsection{Model Development}

The model was formed by regression non-linear analysis, a widely used statistical technique.

The mathematical modeling involved the use of cyclic repetition in search of a mathematical model, starting from simple forms and proceeding to more complex ones, until a mathematical model confirmed to be adequate by Fisher's test is obtained.

The comprehensive analysis of the experimental data showed that the rate of change of variables was proportional to their actual values. We chose to use an exponential function, knowing that the exponential function arises naturally as a mathematical model in situations when the rate of change of a variable is proportional to its actual value.

Using well-known modeling principles as a guidance, a regression equation describing the studied pattern was obtained, [31]:

$\hat{y}=b_{1}+b_{2} \mathrm{e}^{b_{3}+b_{4} x+b_{5} x^{2}}$

where $b_{i}, i=1,2, \ldots, 5$, coefficients obtained by non-linear regression analysis.

Tab. 3 presents the estimated values of the coefficients $b_{i}$ of the non-linear regression mathematical model (1). The second column of the table shows the dispersion of the coefficients of the model $S E\left(b_{i}\right)$.

Table 3 Values of coefficients, and their dispersion, of the non-linear regression mathematical mode

\begin{tabular}{|c|c|c|}
\hline Coeff. & Estimated $b_{\text {i }}$ & $S E\left(b_{i}\right)$ \\
\hline$b_{1}$ & -18.747 & 974.272 \\
\hline$b_{2}$ & 5.650 & 9.694 \\
\hline$b_{3}$ & 1.113 & 54.770 \\
\hline$b_{4}$ & 0.142 & 7.800 \\
\hline$b_{5}$ & 0.002 & 0.379 \\
\hline
\end{tabular}

The adequacy of the non-linear regression model (1) was assessed by Fisher's test, [32]:

$F r=\frac{S S R /(K-1)}{S S E /(N-K)}$, Fisher's test

where: SSR - sum of squares due to regression; $S S E$ - sum of squared errors; $K$ - number of coefficients of the non- 
linear regression mathematical model; $N$ - total number of experimental data points

The regression sum of squares is presented as:

$$
S S R=\sum_{i=1}^{N}\left(\hat{y}_{i}-\bar{y}\right)^{2}
$$

where $\hat{y}_{i}$ are the estimated values of vibrations at the experimental points obtained using the regression mathematical model (1) depending on the sound pressure level.

$\bar{y}=\frac{1}{N} \sum_{i=1}^{N} y_{i}$, mean value of vibration

The value of the regression sum of squares for the present model is: $S S R=1.153180663437412 \mathrm{e}^{+02}$.

The residual sum of squares, the second important element of Fisher's test, is presented as:

$$
S S E=\sum_{i=1}^{N}\left(y_{i}-\hat{y}_{i}\right)^{2}
$$

where $y_{i}$ - the calculated values of vibrations at $N$ points of the experimental design Tab. (2).

The value of the residual sum of squares for the present model is: $S S E=0.375456889119168$.

The value of Fisher's test based on Eq. (2), for the present regression model, is: $F_{\mathrm{r}}=1126.182318611941$.

Knowing that the model is adequate, for the given level of significance $p$, if the condition:

$F_{\mathrm{r}}>F_{\mathrm{t}}$ is satisfied

where: $F_{\mathrm{t}}=3.587433702420495$, the tabular value obtained using the parameters $K, N$ and $p$.

$p=0.95$ - the level of significance used to estimate the adequacy of the mathematical model.
The condition $F_{\mathrm{r}}>F_{\mathrm{t}}$ being satisfied, we can conclude that the regression mathematical model (1) of the exponential form is adequate.

Another indicator of modeling success is the coefficient of determination.

The coefficient of determination is an indicator of whether the regression model is representative, and is based on the analysis of variance. It provides information on the proportion of the variance in output data that is explained by functional dependence versus the so-called residual or unexplained variance. The coefficient of determination is the measure of dependence between the variables $x$ and $y$, and is defined by:

$R^{2}=1-\frac{S S E}{S S T}$

where: $S S T=1.156936571227460 \mathrm{e}^{+02}$

For the present model, this value is: $R=0.997$.

The adjusted coefficient of determination:

$R_{\text {adj }}^{2}=1-\frac{(N-1) S S E}{(N-K) S S T}$

For the present model, the value is: $R_{\text {adj }}^{2}=0.996$.

The coefficient of determination is an indicator of the quality of the regression model.

Given that the degree of determination $R^{2} \approx 1$, there is a high degree of dependence between sound pressure and vibrations ( $x$ and $y$, respectively), which are dealt with in this research.

After its establishment, the model was checked using the experimental data for type- 6306 bearings as well as bearings employed for model development whose $V_{\text {rms }}$ values ranged from 0.28 to $7.1 \mathrm{~mm} / \mathrm{s}$. The results of the model were within the prediction error limits.

The vibration prediction interval, as another indicator of model success, is shown in Fig. 7, as the dashed lines.

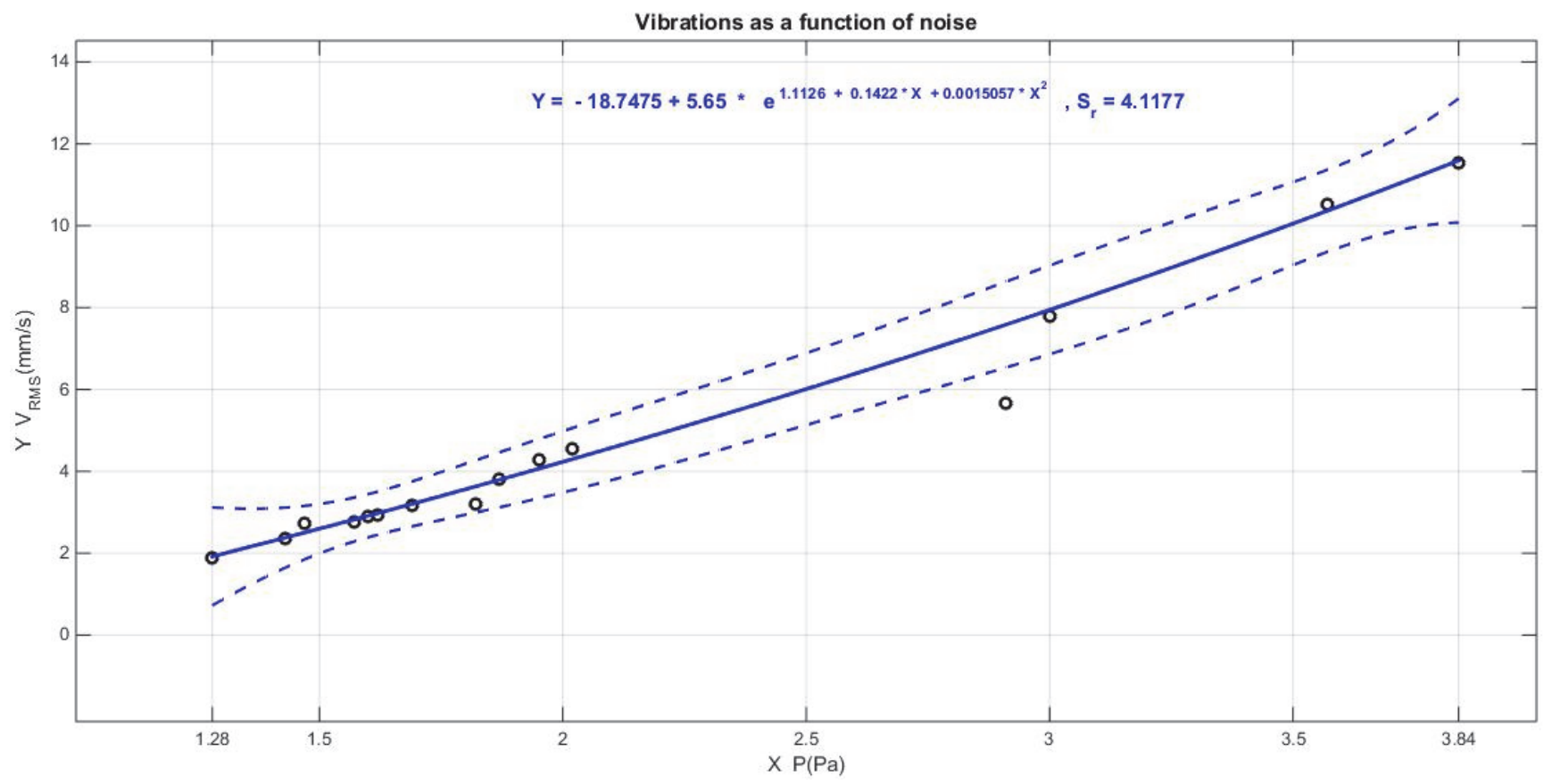

Figure 7 Prediction interval for the regression model 


\subsection{Experimental Data Points to Check the Mathematical Model}

After its establishment, the model was checked using the experimental data for type-6306 bearings of the same category, as well as bearings employed for model formation. The bearings had different degrees of damage. The values of VRMS for these bearings ranged from 0.28 to $7.1 \mathrm{~mm} / \mathrm{s}$. Fig. 8 presents model check results. As shown, three points are within the model prediction limits.
The approach to modeling used here and the model check results lead to the conclusion that the condition of rolling bearings can be evaluated and predicted by monitoring individual parameters i.e. parameters which can be measured in real situations. The developed vibrodiagnostic system and the created model enable the evaluation and prediction of the operating state of a wide range of rolling bearings.

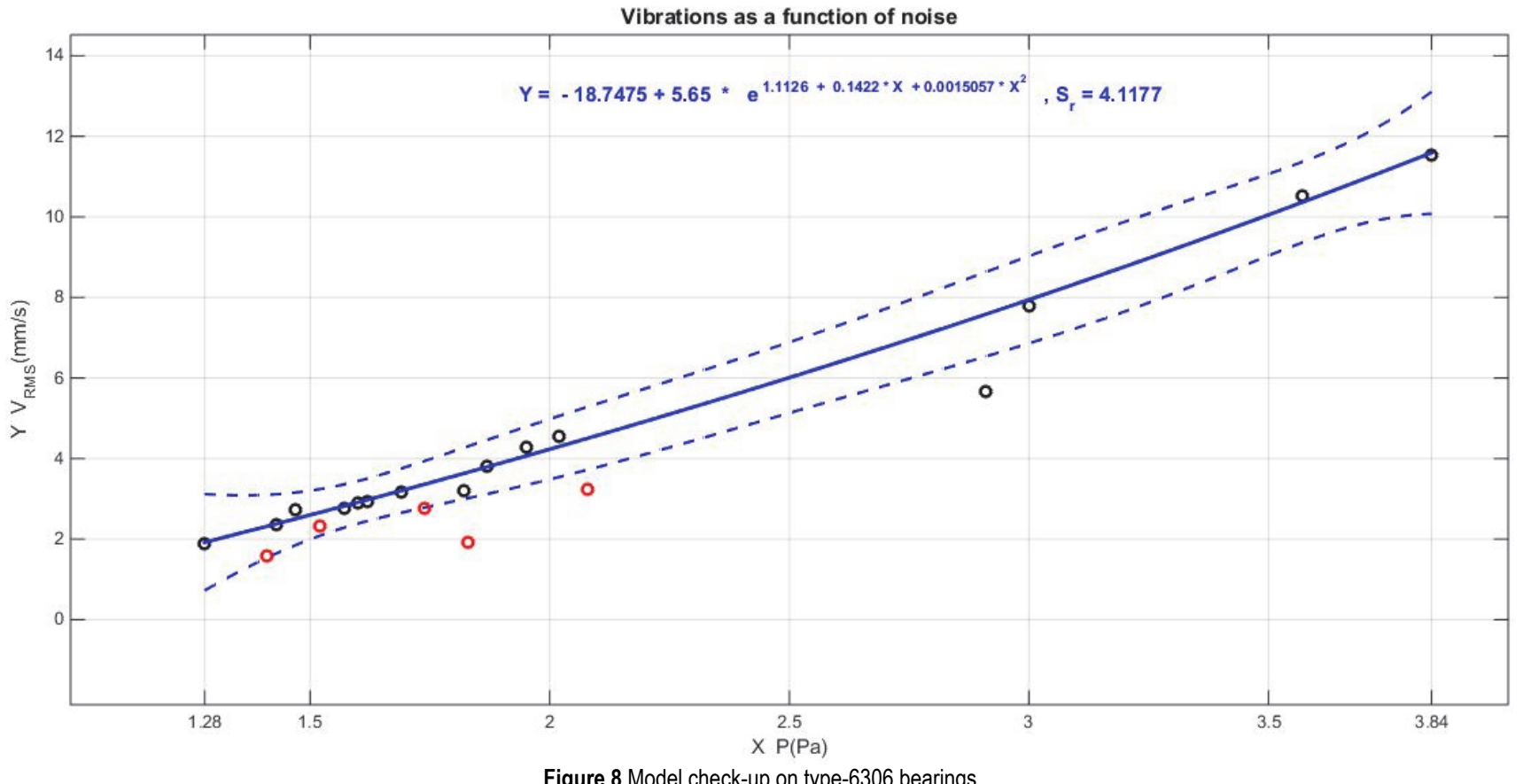

Figure 8 Model check-up on type-6306 bearings

\section{CONCLUSION}

When designing the device for testing and diagnosing the condition of rolling bearings, the main requirement for the device was the ability to simulate loads close to real operating loads. This requirement was satisfied in the constructed device. The equipment was used to perform measurements on damaged bearings in a factorial experiment.

Given the fact that real operating conditions do not allow measurement of all vibrodiagnostic parameters, this paper showed the development of a model that establishes the relationship among these parameters. By this approach, the model enables bearing condition monitoring based on the value of a single parameter.

The model involved the identification of patterns of distribution of the experimental data and their interrelationship based on non-linear regression analysis. The analysis of the experimental data showed that the rate of change of a variable is proportional to the actual value. An exponential function was chosen, since it arises naturally as a mathematical model in such situations.

The developed model makes it possible to evaluate and predict the bearing condition by measuring sound intensity, which is simpler than vibration measurements in real conditions.

The developed vibrodiagnostic system and the created model are able to evaluate and predict the condition of a wide range of rolling bearings. Importantly, the condition of a bearing can be determined during machine operation, i.e. without downtime. As rolling bearings are the most widely used machine elements, monitoring their condition can increase the reliability and performance of the entire mechanical system.

Future research can be focused to define some damage criteria, to be able to predict the remaining useful life of rolling bearings based on the developed model.

\section{Acknowledgements}

This study was supported by the Ministry of Education, Science and Technological Development of the Republic of Serbia, Grant No. 451-03-9/2021-14/200132 with University of Kragujevac - Faculty of Technical Sciences Čačak.

\section{REFERENCES}

[1] Patel, V. N., Tandon, N., \& Pandey, R. K. (2013). Vibration Studies of Dynamically Loaded Deep Groove Ball Bearings in Presence of Local Defects on Races. Procedia Engineering, 64, 1582-1591. https://doi.org/10.1016/j.proeng.2013.09.240

[2] Malla, C. \& Panigrahi, I. (2019). Review of Condition Monitoring of Rolling Element Bearing Using Vibration Analysis and Other Techniques. Journal of Mechanical Science and Technology, 7, 407-414. https://doi.org/10.1007/s42417-019-00119-y 
[3] Du, Q. \& Yang, S. (2007). Application of the EMD method in the vibration analysis of ball bearings. Mechanical Systems and Signal Processing, 21(6), 2634-2644. https://doi.org/10.1016/j.ymssp.2007.01.006

[4] Li, W., Qiu, M., Zhu, Z., Wu, B., \& Zhou, G. (2016). Bearing fault diagnosis based on spectrum images of vibration signals. Measurement Science and Technology, 27(3). https://doi.org/10.1088/0957-0233/27/3/035005

[5] McInerny, S. A. \& Dai, Y. (2003). Basic vibration signal processing for bearing fault detection. IEEE Transactions on Education, 46(1), 149-156. https://doi.org/10.1109/TE.2002.808234

[6] Gupta, P. \& Pradhan, M. K. (2017). Fault detection analysis in rolling element bearing: A review. Materials Today: Proceedings, 4(2A), 2085-2094. https://doi.org/10.1016/j.matpr.2017.02.054

[7] Zarei, J., Tajeddini, M. A., \& Karimi, H. R. (2014). Vibration analysis for bearing fault detection and classification using an intelligent filter. Mechatronics, 24(2), 151-157. https://doi.org/10.1016/j.mechatronics.2014.01.003

[8] Hamadache, M., Lee, D., Mucchi, E., \& Dalpiaz, G. (2018). Vibration-Based Bearing Fault Detection and Diagnosis via Image Recognition Technique under Constant and Variable Speed Conditions. Applied sciences, 8, 1392. https://doi.org/10.1016/j.ymssp.2007.01.006

[9] Li, W., Qiu, M., Zhu, Z., Jiang F., \& Zhou, G. (2017). Fault diagnosis of rolling element bearings with a spectrum searching method. Measurement Science and Technology, 28(9), 095008. https://doi.org/10.1088/1361-6501/aa7b4c

[10] Omoregbee, H. O. \& Heyns P. S. (2018). Fault detection in roller bearing operating at low speed and varying loads using Bayesian robust new hidden Markov model. Journal of Mechanical Science and Technology, 32, 4025-4036. https://doi.org/10.1007/s12206-018-0802-8

[11] Živković, A. M. (2013). Computational and experimental analysis of the behavior of ball bearings for special purposes. $\mathrm{PhD}$ thesis, University of Novi Sad, Faculty of Technical Sciences.

[12] Howard, I. (1994). A Review of rolling element bearing vibration detection, diagnosis and prognosis. DSTO Aeronautical and Maritime Research Laboratory, GPO Box 4331, Melbourne Victoria 3001, Australia.

[13] Sedmak, T. \& Veg, E. (2012). Failure Prevention of Rotating Equipment by Vibrodiagnostics. Structural Integrity and Life, 12(2), 99-104.

[14] Monkova, K. \& Monka, P. (2013). Vibrodiagnostics and its Application in Manufacturing Practice. Applied Mechanics and Materials, 390, 220-224. https://doi.org/10.4028/www.scientific.net/AMM.390.220

[15] Vekteris, V., Jurevičius, M., \& Čereška, A. (2008). Vibrodiagnostics of the components of technological machines. Proceedings of Eighth International Conference on Vibration Measurements by Laser Techniques: Advances and Applications, 70981(B). https://doi.org/10.1117/12.803180

[16] Šiniković, G. B. (2013). Bearing damage detection in ultrasonic domain. $\mathrm{PhD}$ thesis, University of Belgrade, Faculty of Mechanical Engineering.

[17] Nerella, M. J., Ratnam, Ch., \& Rao, V. V. (2017). Study of Detection of Defects in Rolling Element Bearings Using Accoustic Measurement Methods - A Review. SSRG International Journal of Mechanical Engineering (SSRGIJME), 2017, 110-116.

[18] Shibata, K., Takahashi, A., \& Shirai, T. (2000). Fault Diagnosis of Rotating Machinery through Visualisation of Sound Signals. Mechanical Systems and Signal Processing, 14(2), 229-241. https://doi.org/10.1006/mssp.1999.1255

[19] Tandon, N. \& Nakra, B. C. (1992). Comparison of vibration and acoustic measurement techniques for the condition monitoring of rolling element bearings. Tribology International, 25(3), 205-212.
https://doi.org/10.1016/0301-679X(92)90050-W

[20] Tandon, N. \& Choudhury, A. (1999). A review of vibration and acoustic measurement methods for the detection of defects in rolling element bearings. Tribology International, 32, 469-480. https://doi.org/10.1016/S0301-679X(99)00077-8

[21] Henriquez, P., Alonso, J. B., Ferrer M. A., \& Travieso, C. M. (2014). Review of Automatic Fault Diagnosis Systems Using Audio and Vibration Signals. IEEE Transactions on Systems, Man, and Cybernetics: Systems, 44(5), 642-652. https://doi.org/10.1109/TSMCC.2013.2257752

[22] Hasan, Md. J., Manjurul Islam, M. M., \& Kim, J. M. (2019). Acoustic spectral imaging and transfer learning for reliable bearing fault diagnosis under variable speed conditions. Measurement, 138, 620-631. https://doi.org/10.1016/j.measurement.2019.02.075

[23] Nerella, M. J., Ratnam, Ch., \& Rao, V. V. (2018). Fault Diagnosis of a Rolling Element Bearings Using Acoustic Condition Monitoring and Artificial Neural Network Technique. International Research Journal of Engineering and Technology (IRJET), 5(3), 1483-1493.

[24] Ulus, S. \& Erkaya, S. (2016). An Experimental Study on Gear Diagnosis by Using Acoustic Emission Technique. International Journal of Acoustics and Vibration, 21(1), 103-111. https://doi.org/10.20855/ijav.2016.21.1400

[25] Mba, D. (2008). The Use of Acoustic Emission for Estimation of Bearing Defect Size. Journal of Failure Analysis and Prevention, 8, 188-192. https://doi.org/10.1007/s11668-008-9119-8

[26] Ferrando Chacon, J. L., Andicoberry, E. A., Kappatos, V., Papaelias, M., Selcuk, C., \& Gan, T. H. (2016). An experimental study on the applicability of acoustic emission for wind turbine gearbox health diagnosis. Journal of Low Frequency Noise, Vibration and Active Control, 35(1), 6476. https://doi.org/10.1177/0263092316628401

[27] Ahmad, W., Khan, S. A., Manjurul Islam, M. M., \& Kim, J. M. (2019). A reliable technique for remaining useful life estimation of rolling element bearings using dynamic regression models. Reliability Engineering \& System Safety, 184, 6776. https://doi.org/10.1016/j.ress.2018.02.003

[28] Shi, H., Guo, J., Bai, X., Guo, L., Liu, Z., \& Sun, J. (2020). Research on a Nonlinear Dynamic Incipient Fault Detection Method for Rolling Bearings. Applied Sciences, 10(7), 2443. https://doi.org/10.3390/app10072443

[29] Ivković, N., Urošević, V., \& Savić, B. (2020). Implemetation of a non-linear regression model in the diagnostics of the rolling bearings. 26th Conference YU INFO 2020

[30] Levenberg, K. (1944). A Method for the Solution of Certain Non-Linear Problems in Least Squares. Quarterly of Applied Mathematics, 2(2), 164-168. https://doi.org/10.1090/qam/10666

[31] Lourakis, M. I. A. (2005). A brief description of the Levenberg-Marquardt algorithm implemented bylevmar. Institute of Computer Science, Foundation for Research and Technology - Hellas.

[32] Minder, Ch. E. \& Gillmann G. (2011). On Estimating the Fisher Information Matrix in Nonlinear Regression Models. International Journal of Applied Mathematics and Statistics, 24, 98-106.

\section{Contact information:}

\section{Biljana SAVIĆ, Mr, professor}

University of Kragujevac, Faculty of Technical Sciences Čačak,

Svetog Save 65, 32102 Čačak, Serbia

E-mail: biljana.savic@ftn.kg.ac.rs

Vlade UROŠEVIĆ, PhD, full professor

University of Kragujevac, Faculty of Technical Sciences Čačak,

Svetog Save 65, 32102 Čačak, Serbia

E-mail: vlade.urosevic@ftn.kg.ac.rs 
Nebojša IVKOVIĆ, Mr, professor

College of Applied Sciences Užice, Serbia,

Trg Svetog Save 34, 31000 Užice, Serbia

E-mail: nebojsa.ivkovic@vpts.edu.rs

Ivan MILIĆEVIĆ, PhD, associate professor

(Corresponding author)

University of Kragujevac, Faculty of Technical Sciences Čačak,

Svetog Save 65, 32102 Cačak, Serbia

E-mail: ivan.milicevic@ftn.kg.ac.rs

Marko POPOVIĆ, PhD, assistant professor

University of Kragujevac, Faculty of Technical Sciences Čačak,

Svetog Save 65, 32102 Cačak, Serbia

E-mail: marko.popovic@ftn.kg.ac.rs

Nenad GUBELJAK, PhD, full professor

University of Maribor, Faculty of Mechanical Engineering,

Smetanova ulica 17, 2000 Maribor, Slovenia

E-mail: nenad.gubeljak@um.si

Goran ŠINIKOVIĆ, PhD, associate professor

University of Belgrade, Faculty of Mechanical Engineering,

Kraljice Marije 16, 11120 Beograd, Serbia

E-mail: gsinikovic@mas.bg.ac.rs 